\title{
Could Clinical Use of Stimulant Medications Increase Risk for Parkinson's Disease or Other Neurological Sequelae? A Review of the Evidence
}

\author{
Alan A Baumeister* \\ Department of Psychology, Louisiana State University, USA
}

Submission: July 18, 2017; Published: August 04, 2017

*Corresponding author: Alan A Baumeister, Department of Psychology, Louisiana State University, 236 Audubon Hall, Louisiana State University, Baton Rouge, Louisiana 70803, USA, Tel: (225) 578-8745; Email: abaumei@lsu.edu

\begin{abstract}
Millions of children in the United States are treated with stimulant medications for attention/deficit hyperactivity disorder (ADHD). Treatment may begin before school-age and continue for years. All stimulants that are used to treat ADHD have well-established neurotoxic effects in animals, particularly on dopamine neurons. Idiopathic Parkinson's disease (PD) is a neurodegenerative disorder involving (primarily) death of nigrostriatal dopamine neurons. Given these observations, it is reasonable to ask whether children treated for ADHD with stimulants may have an increased risk for later development of PD or other neurological sequelae. This paper reviews the experimental, clinical, and epidemiological evidence that pertains to this question. It is concluded that the weight of the evidence suggests that a linkage between stimulant use and increased risk for PD is plausible.
\end{abstract}

Keywords: Stimulants; ADHD, amphetamine, methamphetamine, Parkinson's Disease

Abbreviations: ADHD: Attention/Deficit Hyperactivity Disorder; PD: Parkinson's Disease Preface

This paper explores a provocative hypothesis: stimulant treatment for attention/deficit-hyperactivity disorder (ADHD) may increase risk for neurological sequelae. It is important to make clear from the outset that the intent here is not to establish the veracity of this hypothesis with certitude. Rather, the goal is to determine whether the hypothesis is plausible. Millions of children and adults in the US alone are receiving stimulant treatment for ADHD. The hypothesized untoward effect of this treatment is Parkinson's disease (PD), a debilitating, progressive, and irreversible neurological disorder. The evidence reviewed here points to a possible link between stimulant exposure and PD. A central premise of this review is that, given the scope and severity of the potential public health threat, the consequences of falsely rejecting this hypothesis are far more serious than the consequences of falsely accepting it. The conclusion of this paper is that the supporting evidence crosses the threshold of plausibility, and, therefore, the hypothesis should be given serious consideration.

\section{Introduction}

PD is a common neurodegenerative disorder of senescence. The principal underlying neuropathology in PD is death of nigrostriatal dopamine neurons. Stimulant medications that are used to treat ADHD have toxic effects on dopamine neurons. Moreover, current trends are toward increasing reliance on types of stimulants (e.g. amphetamines) and formulations (e.g. extended release) that may have more pronounced neurotoxicity than the short acting methylphenidate (Ritalin ${ }^{\text {TM }}$ ) formulation, which was used predominantly in the past. These observations raise the question whether treatment with stimulants may increase risk for later development of PD or other neurological sequelae. For reasons that are difficult to discern, there has been little expressed concern about this possibility in the clinical literature. The evidence reviewed here is suggestive of a possible (plausible) link between stimulant use and PD. Others have, mostly in passing, also called attention to this possibility [1-6]. Given the scope of stimulant medication use in the US and the severity of PD, the mere plausibility of such a link should be cause for concern and an impetus for clinical research designed to address this issue.

\section{Stimulant Use Among US Children for the Treatment Of ADHD}

The practice of using amphetamine and its analogues to treat behavioral disorders in children began in the US in the 1930s [7]. There is little definitive information about the epidemiology of stimulant use for this purpose before the 1970s. Safer and 
Krager [8] reported that in Baltimore County MD schools stimulant medication treatment among students doubled every 4 to seven years between 1971 and 1987. During the early period of this study, stimulant use was confined mostly to elementary school children, but as time went on, the percent of older children treated increased. Between 1971 and 1984 the percent of elementary school students receiving medication for Hyperactive/Inattentive (HA/I) behavior rose from $1.07 \%$ to 5.96\%; between 1975 and 1987 the percent of middle school students receiving medication for $\mathrm{HA} / \mathrm{I}$ rose from $0.5 \%$ to $3.68 \%$; between 1983 and 1987 the percent of high school students receiving medication for $\mathrm{HA} / \mathrm{I}$ rose from $0.21 \%$ to $0.40 \%$. In 1971, among children treated with stimulants for HA/I, $40 \%$ were treated with methylphenidate and $36 \%$ were treated with amphetamine. By 1987 use of methylphenidate rose to $93 \%$ of the total, and that of amphetamine dropped to 3\%. Pemoline (Cylert $^{\mathrm{TM}}$ ) accounted for $1 \%$ to $6 \%$ of prescriptions between its introduction in 1974 and 1987. In a follow up report, the same investigators [9] found that the average duration of stimulant treatment was 7-8 years among high school students, 4-5 years among middle school students, and 2 years among elementary school students. Boys were considerably more likely than girls to be treated with stimulants at the beginning of the study period (by about 10:1). By the end of the study period (1993) this gap had narrowed to about 6:1 [9].

In 2010, the US Center for Disease Control and Prevention reported that, among adolescents (ages 12-19), stimulants were the most common drugs prescribed to this age group, accounting for $6.1 \%$ of all prescriptions [10]. Another recent survey estimated that stimulant use among US children (< age 19) was $2.7 \%$ and $2.9 \%$ in 1997 and 2002, respectively [11]. According to the latter study, in absolute terms, 2.2 million children received stimulant medication in 2002 . The same study reported that stimulant use was highest (4.8\%) among 6 to 12 year-olds. The prevalence of stimulant use in children age 5 or below was $0.3 \%$, about 100,000 children.

In the mid-1990s methylphenidate was the predominant medication used to treat ADHD. A study of 900,000 youths enrolled in US health care programs found that methylphenidate accounted for approximately 80\% of prescriptions for ADHD between 1987 and 1996 [12]. In a national survey, Safer et al. [13] reported a 2.5 fold increase in the use of methylphenidate among "youths" between 1990 and 1995. By mid-1995 about 1.5 million children between the ages 5 and 18 were taking this medication [13].

The specific stimulants used to treat ADHD and their formulations began to change in the 1990s. A large-scale study found a dramatic (7-14 fold) increase in use of amphetamines, particularly d-amphetamine, between 1987 and 1996 [12]. Also, in 1996 a formulation of a 3/1 mixture of $d$ - and l-amphetamine salts, was released (i.e., Adderall ${ }^{\mathrm{TM}}$ ).Other recently released stimulants include methamphetamine $\left(\right.$ Desoxyn $\left.^{\mathrm{TM}}\right)$ and a d-amphetamine prodrug $\left(\right.$ Vyvance $\left.^{\mathrm{TM}}\right)$. All of these medications are now available in extended release forms, as is methylphenidate. During the 1990s, global use of short-acting medications and formulations (i.e., $<8$ hours) declined and global used of longacting medications and formulations (i.e., $>8$ hours) increased, with use of the latter exceeding the former by 2003 [14].

\section{Stimulant Neurotoxicity}

It has long been apparent that the stimulant medications used to treat of ADHD are toxic to dopamine neurons. Most research on stimulant neurotoxicity has focused on methamphetamine because of its widespread illicit abuse. Multiple studies have shown that in rodents, rodent neuronal cell cultures, and nonhuman primates, exposure to methamphetamine causes a dosedependent selective loss of nigrostriatal dopamine neurons. Markers of stimulant-induced dopamine neuron degeneration include decreased tyrosine-hydroxylase, decreased dopamine membrane and vesicular transporters (DAT and VDAT, respectively), decreased striatal dopamine terminals, and decreased striatal dopamine concentration [15-23]. Recently, loss of cell bodies of dopaminergic neurons in the substantia nigra pars compacta following in vivo methamphetamine exposure in rodents has been reported [15]. Liu et al. [20]. Reported that acute exposure to methamphetamine in rats produces "Parkinson's-like behavior" on the rotorod test. Tharsh et al. [5].

proposed that methamphetamine-induced neurotoxicity "...is an ideal toxic candidate to produce an animal model of Parkinson's disease".

The neurotoxicity of racemic- and d-amphetamine is of particular relevance because these drugs are in current widespread to treat ADHD. The experimental literature is clear: these forms of amphetamine are toxic to nigrostriatal dopamine neurons in both rodent and non-human primate models [4,22,24-27]. Moreover, amphetamine-induced disturbances in striatal dopamine have been reported long after exposure ended [22,24,28]. Selemon et al. [29] reported that non-human primates given repeated injections of amphetamine to induce amphetamine-sensitization had pathologic morphologic changes in cortical pyramidal neurons three or more years after amphetamine exposure.

Methamphetamine is more effective than d-amphetamine in releasing striatal dopamine [30]. However, although the results are somewhat mixed, other studies suggest there is little difference between these drugs in toxicity to nigrostriatal neurons $[1,22,27]$. A frequently cited study using non-human primates modeled amphetamine dose amounts used in clinical treatment of ADHD. One group of Squirrel monkeys received a 3:1 mixture of d- vs l- amphetamine twice daily by orogastric gavage for four weeks. Dosage was adjusted to maintain plasma concentrations at clinically relevant levels. Striatal dopamine and VDAT were significantly reduced by amphetamine [4]. 
Among the medications commonly used to treat ADHD, methylphenidate is regarded as the least potent, and perhaps less toxic, medication [28,31-37]. There are complex and incompletely understood pharmacodynamics differences between amphetamine and methylphenidate. Amphetamine was reported to be more potent in increasing extracellular dopamine, but PET studies in both rodents and non-human primates indicated that methylphenidate and amphetamine produced comparable reduction of [11C]-raclopride binding (an index of D2 receptors), indicating no difference in this measure of neurotoxicity [32]. A recent study of methylphenidate revealed that chronic exposure (i.e., 90 days) to moderate doses of this drug in mice produced a $20 \%$ reduction in nigral pars compact a dopamine neurons and activation of nigral microglia. In addition, methylphenidate enhanced the toxicity of nigral dopamine neurons to another dopamine neurotoxin - MPTP [33]. Finally, Moll et al. [34] reported that administration of $2 \mathrm{mg} / \mathrm{kg} /$ day for 2 weeks of methylphenidate in prepubertal rats produced a $50 \%$ decrease in striatal dopamine transporters 45 days after administration. Thus, amphetamine and methylphenidate, like methamphetamine, are toxic to dopamine neurons, and toxicity to all three analogues is demonstrable long after exposure has ended.

The mechanisms that underlie stimulant toxicity to dopamine neurons are unknown. Multiple pathways leading to dopamine cell damage and death are likely. Mitochondrialinduced overproduction oxygen-reactive species and consequent oxidative stress has received the most attention [38-40]. Some studies have reported that amphetamines damage dopamine terminals while sparing cell bodies. A recent study, however, found that methamphetamine causes loss of terminals and pars compact a dopamine soma [15]. Additional evidence indicates that degeneration of nigrostriatal dopamine neurons is caused by both necrosis and apoptosis [15].

Relatively few studies have been conducted on the neurotoxicity of stimulants in humans. Two post-mortem studies of dopamine neurotoxicity in chronic methamphetamine abusers were found. Both studies found evidence of neurotoxicity, including reductions of striatal dopamine, tyrosine hydroxylase, and DAT $[35,36]$. However, differences between the methamphetamine abusers and findings in PD were noted. One study failed to find changes in dopa decarboxylase and VDAT in stimulant-exposed subjects [35]. The other study found that, although methamphetamine abusers had up to a $97 \%$ decrease in striatal dopamine concentrations (well above the threshold considered necessary for emergence of motor symptoms in PD), the relative degree of dopamine reduction in the caudate versus the putamen was reversed that putatively found in PD [36].

Neither study reported whether the methamphetamine abusers were neurologically compromised. However, it is important to note that subjects in both studies were young at the time of death (mean ages in the two studies were 31.4 and 32.5), well below the age at which motor symptoms of PD typically emerge. Moreover, the authors of one study [35] state that their findings do not imply that "...degenerative effects might not have emerged in these subjects later in life". Authors of the other study [36] conclude that "...given the severity of the striatal dopamine reduction in some MA [methamphetamine] users, from a public health perspective attention must also be devoted to the clinical consequences of brain dopamine depletion, irrespective of whether this abnormality is associated with physical loss of the nerve ending." Two studies of stimulant neurotoxicity using positron emission tomography (PET) in living subjects were found. Both reported a significant decrease in DAT among chronic methamphetamine abusers [6,21].

\section{Parkinson's Disease}

$\mathrm{PD}$ is a progressive neuro-degenerative disorder of senescence, though a rare early onset form of Parkinson's disease (EOPD) is also recognized. The incidence and prevalence of PD increase markedly with age. The median age of onset of idiopathic PD is 74 [41]. Diagnosis of PD is usually based on the presence of movement disorders, particularly bradykinesia, rigidity, and resting tremor [42]. The classic neuropathological finding in PD is degeneration of nigrostriatal dopamine neurons, often associated with Lewy body inclusions. Loss of nigrostriatal dopamine neurons is associated with reduced striatal dopamine terminals and a corresponding decrease in striatal dopamine concentration. Typically, a decrease of $70 \%$ or greater in striatal dopamine is required for motor symptoms to become manifest $[42,43]$. Twin and family studies generally find that PD has relatively low heritability, suggesting that environmental factors are etiologically important [44]. Several studies have indicated that the incidence of PD in the US between 1936 and 1966 was relatively stable at about 20 per 100,000 [44]. However, a recent US study found a marked increase in the incidence of $P D$, particularly among men 70 years of age or older. The increase in this group was from 38.8 per 100,000 between 1976 and 1986 to 56.0 per 100,000 between 1996 and 2005 [41].

The classic conception of PD has recently been replaced by an understanding that, as the disease progresses, the neuropathology extends beyond the nigrostriatal dopamine system, and the clinical manifestations include cognitive and psychiatric disturbances [45]. Additionally, a prodromal syndrome that may precede onset of the classic motor symptoms by 10 or more years is now recognized $[42,45,46]$. The Parkinson's prodromal syndrome includes "rapid eye movement sleep behavior disorder" (RBD), impaired sense of smell, constipation, and psychiatric disorders (e.g., depression). Idiopathic RBD, in particular, is now recognized as forerunner of several neurodegenerative diseases, including PD, dementia, and multiple system atrophy [46]. Approximately 38\% of patients diagnosed with RBD develop Parkinson's disease after 5 years. On average, PD develops between 12 and 14 years after diagnosis of RBD $[42,45,46]$. The existence of a prodromal syndrome may 
provide a sensitive way to detect increased risk for PD and other neurological disorders among persons with a history of stimulant exposure before clinical signs become apparent.

\section{Parkinson's Disease and Stimulants}

Evidence for a link between stimulant exposure and PD, albeit indirect and tentative, comes from various sources. Volkow et al. $[6,47]$. Reported that chronic methamphetamine abusers, who had decreased DAT measure by PET, evidenced significant motor slowing and cognitive impairment after protracted abstinence. Callaghan et al. [2] conducted a proactive study of persons at least 30 years of age who were diagnosed as methamphetamine and amphetamine abusers. When examined up to 16 years later, this cohort had increased risk of PD compared to controls matched on various metrics. On the other hand, McCann et al.[3] did not find clinical signs of PD in methamphetamine abusers who had abstained from methamphetamine for three years. These subjects had a significant reduction in DAT in the caudate and putamen, albeit only about half that found in patients with PD. Subjects in this study were on average 37.5 years of age at evaluation, likely too young for motor signs of PD to develop. Indeed, the authors of this study explicitly raised the possibility that their subjects may be at increased risk for developing PD with time.

There is a paucity of data on a possible link between childhood stimulant use and PD. However, such data are not non-existent. Garwood et al. [48] examined the association between early stimulant exposure and subsequent diagnosis of PD. It was reported that prolonged exposure to amphetamines (amphetamine, methamphetamine, and d-amphetamine) was greater in patients with "probable idiopathic Parkinson's disease" than among a comparison group of spouses and care givers. Prolonged exposure was defined as a minimum of twice a week use for three or more months or weekly use for a year or more. Of the 16 subjects with amphetamine exposure seven had been prescribed amphetamines and nine were recreational users. A follow up study by the same group found a small but statistically significant decrease in age of onset of PD in patients who had a history of prolonged exposure to stimulants compared to PD patients who reported no such history(49.8 vs. 53.1, respectively) [49].

Epidemiological studies of PD and stimulant drug use provide correlational evidence for a possible association. As mention previously, Savica et al. [41] reported a dramatic increase in incidence of PD in the US between 1986 and 2005. This increase occurred primarily among men over 70 years of age. Use of stimulants to treat behavioral disorders in children began about 80 years ago [7], and as noted previously, historically, boys are much more likely to have been treated with stimulants than girls [8]. Savica et al. [41] speculated that environmental factors may be responsible for the increase in incidence of $\mathrm{PD}$, including a decrease in smoking in the US (smoking is thought, by some, to have a protective effect on risk for PD), and unspecified environmental or lifestyle changes. They do not mention the possibility that the increase may be related to increased stimulant use.

The previously discussed finding that the incidence of PD is increasing in the US stands in sharp contrast to a report that incidence of PD is actually decreasing in the UK [50]. Although the number of prescriptions for ADHD drugs has increased dramatically in the UK in recent years (by 34 fold), it is still about 10 times lower than in the US [51]. Moreover, the dramatic rise in use of ADHD drugs in the UK is a recent phenomenon. Out of a data base of 14,748 children, only 13 received ADHD medications in the UK between 1992 and 1995 [51]. There has been much speculation about the cause of different trends in incidence of PD in the US and UK, much of it focused on smoking. However, there has been little or no discussion about the possibility that these different geographical trends in PD incidence may be related to differences in stimulant exposure.

After World War II, Japan experienced a methamphetamine epidemic that became so severe that by 1954 an estimated “...1.5 million Japanese were methamphetamine users, of whom 20 percent were so severely dependent that they could not function without the drug" [52]. The phenomenon, "Japan's sole major domestic experience with illegal drugs, and the world's first methamphetamine 'epidemic'" [52], became so severe and pervasive that the period between the end of the war and the beginning of the decline of the epidemic in about 1956 has been labeled the "hiropon age" (the brand name, Philopon, under which methamphetamine was marked in Japan is pronounced "hiropon".) A recent study in Japan revealed that the age adjusted death rates from PD among men began to rise between 1976, reached a peak in 1984 (at 1.66 per 100,00 population), then began to decline slowly until 1992, when the data ended. Assuming that methamphetamine abuse was primarily an adult phenomenon (i.e., occurring primarily among persons 18 years and older) and that the methamphetamine epidemic began in Japan in 1945 at the end of the war, the age at death from PD at the time death rates were at their peak (1984) would have been at least 57 [53].

Another consideration is the possibility that stimulant exposure may increase risk for EOPD. The prevalence of EOPD increased 1.7 fold in Finland between 1995 and 2006 [54]. The authors of this study observed that EOPD clustered in certain geographic regions of Finland, particularly the southwest of the country and the southeastern region of Savo. Because of the geographic clustering, the authors concluded that the increase in EOPD was likely due to genetic factors. The possibility that stimulant use was increased among subjects with EOPD was not addressed. A recent study of drugs in waste water in Finland found that, in all ten cities surveyed, amphetamine was the most common drug detected [55]. Most of the cities surveyed 
fall roughly within the geographic region where EOPD was increased.

\section{Discussion}

It may be useful to divide stimulant treated persons in the US into two cohorts:

I. Those treated before the 1990s, and

II. Those treated after the 1990s.

The latter cohort may be at greater risk for the eventual development of PD and other neurologic sequelae due to the increased use of stimulants and to changes in the types and formulations of stimulants used. But, persons in this cohort would only be about 20 to 30 years of age at the time of this writing. As PD is most often a disease of senescence, the younger cohort is very likely too young to manifest motor signs of PD. Nevertheless, this does not preclude the possibility that the 1990s cohort may have ongoing stimulant-related latent, insidious pathological processes that presage the eventual development of neurologic sequelae. As noted above, the existence of a prodromal syndrome may provide a means to detect such process among persons too young to exhibit clinical signs.

For the older cohort signs of PD may now be detectable. Indeed, as described above, recent years have witnessed a dramatic increase in the incidence of PD among men in the US 70 years of age or older. No such increases were found among older women. As previously noted, historically, boys have been far more likely to be treated with stimulants than girls. This may account, in part, for the reported differences between men and women in recent US PD incidence trends.

As reviewed above, studies in animals show unambiguously that the stimulants used to treat ADHD are toxic to nigrostriatal dopamine neurons. The relevance of these studies to the clinical situation has been dismissed by some on the ground that stimulant doses in animal studies far exceed those used in clinical practice. While this is true of some experimental studies, it is not true of all. Moreover, exposure regimens that have been used in animal studies may actually be an insufficient model of clinical treatment. Maintenance therapy is now considered to be the most effective way to treat ADHD. This, along with increasing reliance on long-acting formulations, means that stimulant exposure in some children is chronic and continuous [1]. The animal studies of stimulant neurotoxicity that have been conducted to date do not even come close to replicating such chronic and continuous exposure. Also, most experimental studies have used adult animals. In clinical practice, stimulants are usually prescribed during the developmental period $(<19$ years of age). It is possible that the developing brain is more sensitive to stimulant neurotoxicity than the adult brain.

Relatively little research has been conducted on the neurotoxicity of stimulants in humans. However, the extant clinical research does indicate that these drugs are toxic to nigrostriatal dopamine neurons. Moreover, a few clinical studies suggest an association between stimulant exposure and neurologic findings, including PD. Epidemiological findings also hint of a correlation between stimulant exposure and PD. Stimulant use has historically been greatest in the US and the incidence of PD in the US is increasing among older men. In contrast, in the UK, where treatment of ADHD with stimulants is a recent development, and still far less common than in the US, the incidence of PD appears to be decreasing. Age-adjusted death rates from PD among men in Japan following a postwar methamphetamine epidemic rose sharply between 1976 and 1992. And, EOPD may be increasing in Finland in geographic regions where waste water analyses indicate that stimulant exposure is high.

\section{Conclusion}

The evidence reviewed here, while far from conclusive, is sufficient to suggest a plausible link between medical use of stimulants and an increased risk for neurological sequelae, including PD. Thus, it would seem both prudent and urgent to conduct future research to assess this possibility.

\section{Acknowledgment}

The author wishes to thank Alexander Rader for his assistance researching this paper.

\section{References}

1. Berman SM, Kuczenski R, McCracken JT, London ED (2009) Potential adverse effects of amphetamine treatment on brain and behavior. Mol Psychiatry 14(2): 123-142.

2. Callaghan RC, Cunningham JH, Sykes J, Kish SJ (2012) Increased risk of Parkinson's disease in individuals hospitalized with conditions related to the use of methamphetamine or other amphetamine-type drugs. Drug Alcohol Depend 120(1-3): 35-40.

3. McCann UD, Wong DF, Yokoi F, Villemagne V, Dannals RF, et al. (1998) Reduced striatal dopamine transport density in abstinent methamphetamine and methcathinone users: evidence from positron emission tomography studies with $\left[{ }^{11} \mathrm{C}\right]$ WIN-35,428. J Neurosci 18(20): 8417-8422.

4. Ricaurte GA, Mechan AO, Yuan J, Hatzidimitriou g, Xie T, et al. (2005) Amphetamine treatment similar to that used in the treatment of adult attention-deficit/hyperactivity disorder damages dopaminergic nerve endings in the striatum of adult nonhuman primates. J Pharmacol Exp Ther 315: 91-98.

5. Thrash B, Thiruchelvan K, Ahuja M, Suppiramaniam, V Dhanasekaran M (2009) Methamphetamine-induced neurotoxicity: the road to Parkinson's disease. Pharmacological Rep 61(6): 966-977.

6. Volkow ND, Chang L, Wang G (2001) Association of dopamine transporter reduction with psychomotor impairment in methamphetamine abusers. Am J Psychiat 158: 377-382.

7. Baumeister AA, Henderson K, LeePow J, Advokat C (2012) The early history of the neuroscience of attention-deficity/hyperactivity disorder. J Hist Neurosci 22(3): 263-279.

8. Safer DJ, Krager JM (1988) A survey of medication treatment for hyperactive/inattentive students. J Am Med Assoc 260(15): 22562258. 
9. Safer DJ, Krager JM (1994) The increased rate of stimulant treatment for hyperactive/inattentive students in secondary schools. Pediatrics 94(4 pt 1): 462-464.

10. Dillon GQ, Burt VL (2010) Prescription drug use continues to increase: U.S. prescription Drug data 2007-2008. NCHS data brief, no 42 Hyattsville, MD: National Center for Health Statistics, 2010.

11. Zuvekas SH, Vitiello B, Norquist GS (2006) Recent trends in stimulant medication use among U.S. children. Am J Psychiatry 163(4): 579-585.

12. Zito JM, Safer DJ, dosReis S, Gander JF, Soeken k, et al. (2003) Psychotropic practice patterns for youth. Arch Pediatric Adolesc Med 157(1): 17-25.

13. Safer DJ, Zito JM, Fine EM (1996) Increased methylphenidate usage for attention deficit disorder in the 1990s. Pediatrics 98(3 pt 1): 1084 1088.

14. Scheffler RM, Hinshaw SP, Modrek S, Levine P (2007) The global market for ADHD medications. Health Affairs 26(2): 450-457.

15. Ares-Santos S, Granado N, Espadas I, Martinez-Murillo R, Moratalla R (2013) Methamphetamine causes degeneration of dopamine cell bodies and terminals of the nigrostriatal pathway evidenced by silver staining. Neuropsychopharmacol 307(5): 1-15.

16. Fasciano J, Hitzidimitriou G, Yuan J, Katz JL, Ricaurte GA (1997) $\mathrm{N}$-methylation dissociates methamphetamine's neurotoxic and behavior pharmacologic effects. Brain Res 771(1): 115-120.

17. Guilarte TR (2001) Is methamphetamine abuse a risk factor in Parkinsonism? Neurotoxicology 22(6): 725-731.

18. Johnson-Davis KL, Hanson GR, Keefe KA (2002) Long-term postsynaptic consequences of methamphetamine on preprotachykinin mRNA expression. J Neurochem 82(6): 1472-1479.

19. Kanthasamy K, Gordon R, Jin H, Syed Ali, A G Kanthaswamy, et al. (2011) Neurotropic effect of Resveratrol against methamphetamineinduced dopaminergic apoptotic cell death in a cell cultural model of neurotoxicity. Curr Neuropharmacol 9: 49-53.

20. Liu Z, Shi Z, Liu J, Wang Y (2014) HIV transactivator of transcription enhances methamphetamine-induced Parkinson's-like behavior in rats. NeuroReport 25: 860-864.

21. McCann UD, Ricaurte GA (2004) Amphetamine neurotoxicity: accomplishments and remaining challenges. Neurosci Biobehav Rev 27(8): 821-826

22. Melega WP, Raleigh MJ, Stout DB, Lacan G, Huang S, et al. (1997) Recovery of striatal dopamine function after acute amphetamine and methamphetamine-induced neurotoxicity in the vervet monkey. Brain Res 766(1-2): 113-120.

23. Ricaurte GA, Seiden LS, Schuster CR (1984) Further evidence that amphetamines produces long-lasting dopamine neurochemical deficits by destroying dopamine nerve fibers. Brain Res 303(2): 359364 .

24. Ellison G, Eison MS, Huberman HS, Daniel F (1978) Long-term changes in dopaminergic innervation of caudate nucleus after continuous amphetamine administration. Science 201(4352): 276-278.

25. Ridley RM, Baker HF, Owen F, Cross AJ, Crow TJ (1982) Behavioral and biochemical effects of chronic amphetamine treatment in the vervet monkey. Psychopharmacol 78(3): 245-251.

26. Robinson TE, Camp DM (1987) Long-lasting effects of escalating doses of d-amphetamine on brain monoamines, amphetamineinduced stereotyped behavior and spontaneous nocturnal locomotion. Pharmacol Biochem Behav 26(4): 821-827.

27. Segal DS, Kuczenski R (1997) Repeated binge exposure to amphetamine and methamphetamine: Behavioral and neurochemical characterization. J Pharmacol Exp Ther 282(2): 561-573.

28. Yuan J, McCann U, Ricaurte G (1997) Methylphenidate and brain dopamine neurotoxicity. Brain Res 767(1): 172-175.

29. Selemon LD, Begović A, Goldman-Rakic PS, Castner SA (2007) Amphetamine sensitization alters dendritic morphology in prefrontal cortical pyramidal neurons in the non-human primate. Neuropsychopharmacol 32(4): 919-931.

30. Goodwin JS, Larson GA, Swant J (2009) Amphetamine and methamphetamine differentially affect dopamine transporters in vitro and in vivo. J Biol Chem 284(4): 2978-2989.

31. Kuczenski R, Segal DS (1997) Effects of methylphenidate on extracellular dopamine, serotonin, and norepinephrine: comparison with amphetamine. J Neurochem 68(5): 2032-2037.

32. Schiffer WK, Volkow ND, Fowler JS, Alexoff DL, Logan J, et al. (2006) Therapeutic doses of amphetamine or methylphenidate differentially increased synaptic and extracellular dopamine. Synapse 59(4): 243251.

33. Sadasivan S, Pond BB, Pani AK, Qu C, Jiao Y, et al. (2012) Methylphenidate exposure induces dopamine neuron loss and activation of microglia in the basal ganglia of mice. PLoS ONE. 7(3): e33693.

34. Moll GH, Hause S, Rüther E, Rothenberer A, Huether G (2001) Early methylphenidate administration to young rats causes persistent reduction in the density of striatal dopamine transporters. J Child Adolesc. Psychopharmacol 11(1): 15-24.

35. Wilson JM, Kalasinsky KS, Levey AI (1996) Striatal dopamine nerve terminal and markers in human, chronic methamphetamine users. Nat Med 2(6): 699-703.

36. Moszczynska A, Fitzmaurice P, Ang L (2004) Why is parkinsonism not a feature of human methamphetamine users. Brain 127: 363-370.

37. Seiden LS, Sabol KE, Ricaurte GA (1993) Amphetamine: effects on catecholamine systems and behavior. Ann Rev Pharmacol Toxicol 32: 639-677.

38. Brown JM, Yamamoto BK (2003) Effects of amphetamines on mitochondrial function: role of free radicals and oxidative stress. Pharmacol Ther 99(1): 45-53.

39. Tata DA, Yamamoto BK (2007) Interactions between methamphetamine and environmental stress: role of oxidative stress, glutamate, and mitochondrial dysfunction. Addiction 102 (Suppl 1): 49-60.

40. Yamamoto BK, Bankson MG (2005) Amphetamine neurotoxicity: Cause and consequence of oxidative stress. Crit Rev Neurobiol 17: 87-117.

41. Savica R, Grossardt BR, Bower JH, Ahlskoy JE, Rocca WA (2016) Time trends in the incidence of Parkinson's Disease. JAMA Neurology 73(8): 981-989.

42. Kalia LV, Lang AE (2015) Parkinson's disease. Lancet 386: 896-912.

43. Wilson JM, Levey AI, Rajput A (1996) Differential changes in neurochemical markers of striatal dopamine nerve terminals in idiopathic Parkinson's disease. Neurology 47(6): 718-726.

44. Rajput AH, Birdi S (1998) Epidemiology of Parkinson's Disease. Parkinsonism Rel Dis 3: 175-186.

45. Goldman JG, Postuma R (2014) Premotor and non-motor features of Parkinson's disease. Curr Opin Neurol 27(4): 434-441.

46. Mahlknecht P, Seppi K, Poewe W (2015) The concept of prodromal Parkinson's disease. J Parkinson's Dis 5(4): 681-697.

47. Volkow ND, Chang L, Wang G, Flwler JS, Sedler M, et al. (2001) Loss of dopamine transporters in methamphetamine abusers recovers with protracted abstinence. J Neurosci 21: 9414-9418. 
48. Garwood ER, Bekele W, McCulloch CE, Christine CW (2006) Amphetamine exposure is elevated in Parkinson's disease. Neurotoxicology 27(6): 1003-1006.

49. Christine CW, Garwood ER, Lauren BS, Schrock LE, Austin DE, et al (2010) Parkinsonism in patients with a history of amphetamine exposure. Mov Dis 25(2): 228-231.

50. Horsfall L, Petersen I, Walters K, Schrag A (2013) Time trends in incidence of Parkinson's disease diagnosis in UK primary care. J Neurol 260(5): 1351-1357.

51. Beau-Lejdstrom R, Douglas I, Evans SJW, Smeeth L (2017) Latest trends in ADHD drug prescription in the UK: prevalence, incidence, and persistence. BMJ Open.
52. Kingsberg M (2013) Methamphetamine solution: Drugs and the reconstruction of Nation in Postwar Japan. J Asians Studies 72: 141162.

53. Yaneko Y, Kaneo R (1995) Rising mortality from Parkinson's disease in Japan, 1952-1992. Acta Neurol Scand 91(suppl ): 169-176.

54. Ylikotila P, Tlirikka T, Moilanen JS, Kääriälinen H, Majamaa K (2015) Epidemiology of early-onset Parkinson's disease in Finland. Parkinsonism Rel Dis 21: 938-942.

55. Kankaanpää A, Ariniemi K, Heinonen M, Kuoppasalmi K, Gunnar T (2014) Use of illicit stimulant drugs in Finland: A wastewater study in ten major cities. Sci Total Environ 487: 696-702.

\section{Your next submission with Juniper Publishers will reach you the below assets}

- Quality Editorial service

- Swift Peer Review

- Reprints availability

- E-prints Service

- Manuscript Podcast for convenient understanding

- Global attainment for your research

- Manuscript accessibility in different formats

( Pdf, E-pub, Full Text, Audio)

- Unceasing customer service

Track the below URL for one-step submission _ https://juniperpublishers.com/online-submission.php 